\title{
The Danish Inguinal Hernia database
}

This article was published in the following Dove Press journal:

Clinical Epidemiology

25 October 2016

Number of times this article has been viewed

\author{
Hans Friis-Andersen ${ }^{1,2}$ \\ Thue Bisgaard 2,3 \\ 'Surgical Department, Horsens \\ Regional Hospital, Horsens, \\ Denmark; ${ }^{2}$ Steering Committee, \\ Danish Hernia Database, ${ }^{3}$ Surgical \\ Gastroenterological Department \\ 235, Copenhagen University Hospital, \\ Hvidovre, Denmark
}

Aim of database: To monitor and improve nation-wide surgical outcome after groin hernia repair based on scientific evidence-based surgical strategies for the national and international surgical community.

Study population: Patients $\geq 18$ years operated for groin hernia.

Main variables: Type and size of hernia, primary or recurrent, type of surgical repair procedure, mesh and mesh fixation methods.

Descriptive data: According to the Danish National Health Act, surgeons are obliged to register all hernia repairs immediately after surgery (3 minute registration time). All institutions have continuous access to their own data stratified on individual surgeons. Registrations are based on a closed, protected Internet system requiring personal codes also identifying the operating institution. A national steering committee consisting of 13 voluntary and dedicated surgeons, 11 of whom are unpaid, handles the medical management of the database.

Results: The Danish Inguinal Hernia Database comprises intraoperative data from $>130,000$ repairs (May 2015). A total of 49 peer-reviewed national and international publications have been published from the database (June 2015).

Conclusion: The Danish Inguinal Hernia Database is fully active monitoring surgical quality and contributes to the national and international surgical society to improve outcome after groin hernia repair.

Keywords: nation-wide, recurrence, chronic pain, femoral hernia, surgery, quality improvement

\section{Introduction}

Groin hernia repair is the most frequently performed procedure in gastrointestinal surgery with 12,000 operations per year in Denmark. ${ }^{1}$ The Danish Hernia Database consists of two databases: The Inguinal Hernia Database and The Ventral Hernia Database.

Both provide long-term monitoring on nation-wide surgical quality in unselected patients.

The Danish Inguinal Hernia Database reflects daily clinical life and as such offers big data with high external validity with emphasis on recurrence, ${ }^{1-7}$ optimizing surgical technique, ${ }^{2,5,6}$ and characterization of and intervention against chronic pain and sexual dysfunction. ${ }^{8-12}$ As a result, the database has achieved national and international attention due to the contribution of scientific evidence to improve surgical outcome after groin hernia repair. The main focus of the Danish Inguinal Hernia Database has been and still is postoperative risk of recurrence, optimal surgical techniques, chronic pain, sexual dysfunction, and convalescence.

\author{
Correspondence: Hans Friis-Anderse \\ Surgical Department, Horsens Regional \\ Hospital, Sundvej 30, DK-8700 Horsens, \\ Denmark \\ Tel +4578426222 \\ Fax +457842 6399 \\ Email hanfri@rm.dk
}

Clinical Epidemiology 2016:8 52I-524 (Thematic series on clinical quality databases in Denmark) $\mathbf{5 2 \text { I }}$ (c) (1) (2) $\odot 2016$ Fris-Andersen and Bisgard. This work is pulished and licensed by Dove Medical Press Limited. The full terms of this license are available at https://www. cc. accessing the work you hereby accept the Terms. Non-commercial uses of the work are permitted without any further permisision from Dove Medical Press Limited, provided the work is property

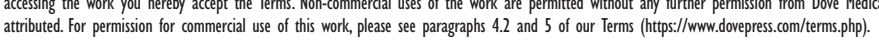

Dovepress

http://dx.doi.org/10.2147/CLEP.S99512 


\section{History}

Before the database was established, hernia recurrence was observed in $>10 \%$ of patients. Within the first couple of years of registration in the database combined with national discussions to improve surgical technique, the reoperation rate was reduced to $2 \%-3 \% .^{1,2}$ The initiative to start the Danish Inguinal Hernia Database was launched in 1997 by a group of dedicated Danish hernia surgeons. From 1998, the database collected prospective nation-wide intraoperative data. From the very start, registrations were promoted by two annual national conferences and interim scientific steering group meetings. The focus of these meetings was and is optimization of surgical quality and techniques, and initiatives to avoid and treat chronic pain. Over the years, these two focus points have been the main drive for conducting scientific studies based on nation-wide database results and detailed followup substudies. From 1998 to 2006, the database employed a full-time research fellow and a part-time secretary. ${ }^{1}$

In the early years, the database was based on a onepage paper-form with brief structured questions (hospital/ clinic, type of procedure, type of anesthesia, operative findings, and whether repair was performed for a primary or recurrent hernia). From 2006 onward, registrations have been managed via a closed Internet system. The surgeon registers intraoperative variables immediately after surgery. Data are validated against data from the National Hospital Administrative System and the National Patient Registry (data matching). This match is based on the use of a unique patient-specific social security number allowing patients to be followed from birth to death. The latter institutions collect prospective basic clinical information (procedure, diagnosis, complications, etc) from all hospital contacts in Denmark. Hospital costs are only covered if operations are coded and registered in these institutions. Since more than $95 \%$ of all operations in Denmark are conducted in public institutions, follow-up is close to $100 \%$.

\section{Aim}

Since its establishment, the primary aim of the database has been to reduce the risk of hernia recurrence and to monitor and improve surgical outcome in a broader term after groin hernia repair.

\section{Study population}

All patients $\geq 18$ years living in Denmark are eligible. The database comprises both primary and recurrent groin repair (lateral, medial, femoral, and obturator hernias). Data are restricted to intraoperative variables.

\section{Main variables}

The current version of the database registers surgical setting (private, public, repair during hospitalization, or same day surgery), type of anesthesia, and intraoperative herniaspecific data (Table 1).

Compared with other hernia-specific databases such as the Swedish Hernia Database, the number of variables in the Danish database is smaller and is based on fewer scientific hypotheses.

\section{Follow-up}

Repeated registrations of subsequent inguinal hernia repair, with repair as a proxy for recurrence, allow lifelong monitoring of data on risk of recurrence. ${ }^{7}$ For other clinical outcomes (pain, convalescence, sexual dysfunction, etc), follow-up is performed by cross-matching cohort data from the Hernia Database with the national clinical databases, by mailed personal questionnaires, and by manual reviews of patients' hospital records as described in detail elsewhere. ${ }^{7}$

Constant monitoring of specific quality indicators (reoperation rate, use of mesh, etc) allows analysis of variations and implementation of relevant actions if deemed necessary. During 2007 and 2008, we found that women who had Lichtenstein procedure performed had two to three times higher reoperation rate than men. As a consequence, the steering committee recommended that groin hernia in women should be treated laparoscopically resulting in a sharp decrease in reoperation rate the following years.

\section{Results}

The Danish Inguinal Hernia Database comprises intraoperative data from $>130,000$ repairs (May 2015). A total of 49 peer-reviewed national and international publications have been published, a full list can be found on www. herniedatabasen.dk. The database also publishes annual public reports on surgical quality on the Internet. The main results have contributed to both national and international reduction of the recurrence rate, reduced convalescence, increased understanding of what causes chronic pain, reduced risk of chronic pain and sexual dysfunction, improved surgical treatment of a recurrent groin hernia, and increased knowledge of risk factors for recurrence. ${ }^{1-15}$

During the first 8 years, $90 \%-95 \%$ of all groin hernia repairs in Denmark were registered in the database. From 2007, the structural control of the Inguinal Hernia Database was transferred to a government system. The change from a paper to an Internet-based system resulted in severe logistic and technical challenges. As a result, the national registration 
Table I Data variables entered to Inguinal Hernia Database (January I, 20I5)

\begin{tabular}{llll}
\hline General & Anesthesia & Hernia characteristics & Procedure \\
\hline Date & Spinal & Right-left & Type of open repair \\
Epidural & Size (EHS, I-3 fingers) & Type of endoscopic repair \\
Local alone & Primary - recurrent & Tumber of recurrences & Type of mesh \\
Surgeon & General & Direct-indirect & Type of mesh fixation \\
Ambulatory & Pantaloon-sliding & \\
Nonambulatory & Femoral & Combination femoral-groin and & \\
Elective/emergency & & other types of inguinal hernia &
\end{tabular}

Notes: EHS (European Hernia Classification of defect size and type of hernia: I, one finger; 2, two fingers; 3, three fingers or more and type of hernia: M, medial; L, lateral; $F$, femoral; O, other).

Abbreviation: EHS, European Hernia Society.

rate fell to $\sim 75 \%$. Due to a sustained effort by dedicated Danish surgeons and the steering committee, the registration rate has again reached 90\% (May 2015). The same tendency was observed in the Danish Ventral Hernia Database.

\section{Examples of research areas}

- No-mesh versus mesh-based inguinal hernia repair. Results from the database demonstrated that outcome in terms of recurrence was improved by using a mesh repair.

- Laparoscopic or open surgical techniques. Results from the database demonstrated that recurrent laparoscopic repair was equal to open repair, that the risk of recurrence after open repair can be reduced by a laparoscopic repair and vice versa.

- Limiting factors and intervention to reduce sick leave after inguinal hernia repair. Results from the database demonstrated that convalescence and sick leave was no more than median 2-3 days and that early ambulation ( $0-2$ days postoperatively) was without increased risk of complications or risk of recurrence.

- Optimal treatment of femoral hernia repair. Results from the database demonstrated femoral hernia repair should preferably be laparoscopic.

- Characterization of and intervention against chronic pain and sexual dysfunction. Based on patients registered in the database, patients were followed and characterized for chronic pain (5\%-10\%) and surgical treatment improved chronic pain in $70 \%$ of the patients.

\section{Administrative issues and funding}

The Hernia Database has been funded by public appropriations since its establishment. From 1997 to 2007, all operational aspects of the database were handled by the steering committee. In 2007, Internet-based registration was introduced and in 2010 control of the economy was transferred to Regionernes Kliniske Kvalitetsudviklings Program. As a result, government organizations now control the majority of core structural tasks within the database. Over the last 5 years, there has been a drastic reduction of the funding available to the steering committee, that is, $\sim 22,000$ Euros covering fees, travel, and meeting expenses. Data analyses, quality reports, and scientific contributions are based on voluntary work.

The basis for all clinical databases in Denmark is the unique individual social security number. Unfortunately, this usage has been politically questioned in order to respect civil privacy by avoiding central health monitoring. If the database use of social security numbers is discontinued, it will destroy the unique potential of the clinical databases to improve the health of Danish citizens.

\section{Conclusion}

The Danish Inguinal Hernia Database is fully active and provides prospective long-term monitoring of surgical quality while contributing to the scientific surgical world and improving results after groin hernia repair. Future challenges will be education of hernia surgeons and continually improving all aspects of groin hernia repair with emphasis on recurrence and chronic pain.

\section{Acknowledgments}

Professor, PhD Henrik Kehlet and Chief Surgeon, DMSc Morten Bay-Nielsen are cordially thanked for their initiative to launch the Inguinal Hernia Database and for their enormous efforts over the years within the database. This paper was funded by the Program for Clinical Research Infrastructure (PROCRIN) established by the Lundbeck Foundation and the Novo Nordisk Foundation and administered by the Danish Regions. 


\section{Disclosure}

The authors report no conflicts of interest in this work.

\section{References}

1. Bay-Nielsen M, Kehlet H, Strand L, et al. Quality assessment of 26,304 herniorrhaphies in Denmark: a prospective nationwide study. Lancet. 2001;358:1124-1128.

2. Bay-Nielsen M, Kehlet H, Steering Committee of the Danish Hernia Database. Establishment of a national Danish Hernia Database: preliminary report. Hernia. 1999;3:81-83.

3. Kehlet H, Bay-Nielsen M. Have we defeated the recurrence in the groin? An epidemiological approach: Denmark. In: Hernia Meshes, SchumpelickV, Nyhus LM, editors. Berlin: Springer Verlag; 2003:13-20.

4. Bay-Nielsen M, Thomsen H, Andersen FH, et al. Convalescence after inguinal herniorrhaphy. Br J Surg. 2004;91:362-367.

5. Bisgaard T, Bay-Nielsen M, Christensen IJ, Kehlet H. Risk of recurrence 5 years or more after primary Lichtenstein mesh and sutured groin hernia repair. Br J Surg. 2007;94:1038-1040.

6. Bisgaard T, Bay-Nielsen M, Kehlet H. Re-recurrence after operation for recurrent groin hernia. A nationwide eight years follow-up study on the role of repair. Ann Surg. 2008;247:707-711.

7. Helgstrand F, Rosenberg J, Kehlet H, Strandfelt P, Bisgaard T. Reoperation versus clinical recurrence rate after ventral hernia repair. Ann Surg. 2012;256:955-958.
8. Bay-Nielsen M, Perkins FM, Kehlet H. Pain and functional impairment 1 year after inguinal herniorrhaphy: a nationwide questionnaire study. Ann Surg. 2001;233:1-7.

9. Bay-Nielsen M, Nilsson E, Nordin P, Kehlet H. Chronic pain after open mesh vs. sutured repair of indirect groin hernia in young males. $\mathrm{Br} J$ Surg. 2004;91:1372-1376.

10. Aasvang EK, Møhl B, Bay-Nielsen M, Kehlet H. Pain-related sexual dysfunction after groin herniorrhaphy. Pain. 2006;122:258-263.

11. Aasvang EK, Brandsborg B, Christensen B, Jensen TS, Kehlet H. Neurophysiological characterisation of postherniorrhaphy pain. Pain. 2008;137:173-181.

12. Bischoff JM, Linderoth G, Aasvang EK, Werner MU, Kehlet H. Dysejaculation after laparoscopic groin herniorrhaphy: a nationwide questionnaire study. Surg Endosc. 2012;26:979-983.

13. Vad MV, Frost P, Bay-Nielsen M, Svendsen SW. Impact of occupational mechanical exposures on risk of lateral and medial groin hernia requiring surgical repair. Occup Environ Med. 2012;69:802-809.

14. Burcharth J, Pedersen MS, Bisgaard T, Pedersen CB, Rosenberg J. Nationwide prevalence of groin hernia repair. PLoS One. 2013;8: e54367.

15. Kjaergaard J, Bay-Nielsen M, Kehlet H. Mortality following emergency groin hernia surgery in Denmark. Hernia. 2010;14:351-355.
Clinical Epidemiology

\section{Publish your work in this journal}

Clinical Epidemiology is an international, peer-reviewed, open access, online journal focusing on disease and drug epidemiology, identification of risk factors and screening procedures to develop optimal preventative initiatives and programs. Specific topics include: diagnosis, prognosis, treatment, screening, prevention, risk factor modification,

Submit your manuscript here: http://www.dovepress.com/clinical-epidemiology-journal

\section{Dovepress}

systematic reviews, risk \& safety of medical interventions, epidemiology \& biostatistical methods, and evaluation of guidelines, translational medicine, health policies \& economic evaluations. The manuscript management system is completely online and includes a very quick and fair peer-review system, which is all easy to use. 